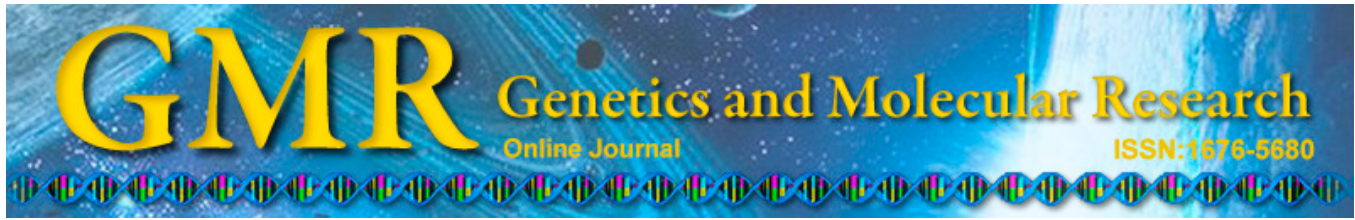

\title{
Genetic association between the $H L A-G$ 14-bp insertion/deletion polymorphism and the recurrent spontaneous abortions in Saudi Arabian women
}

\author{
S.Y. Al Omar' ${ }^{1}$, L. Mansour ${ }^{1,2}$, A.F. Alkhuriji ${ }^{1}$, S. Alwasel ${ }^{1}$ and S. Al-Qahtani ${ }^{3}$ \\ 'Department of Zoology, College of Science, King Saud University, Riyadh, \\ Saudi Arabia \\ ${ }^{2}$ Unité de Recherche de Biologie Intégrative et Ecologie Évolutive et \\ Fonctionnelle des Milieux Aquatiques, Département de Biologie, \\ Faculté des Sciences de Tunis, Université De Tunis El Manar, Tunisia \\ ${ }^{3}$ Depatment of Physiology, College of Medicine, Jazan University, Saudi Arabia
}

Corresponding author: L. Mansour

E-mail: lamjed.mansour@gmail.com

Genet. Mol. Res. 14 (1): 286-293 (2015)

Received March 14, 2014

Accepted September 27, 2014

Published January 23, 2015

DOI http://dx.doi.org/10.4238/2015.January.23.2

ABSTRACT. The non-classical class I human leukocyte antigen (HLA)-G molecule was found to be predominately expressed in the extravillous cytotrophoblasts at the fetal-maternal interface during pregnancy. This molecule is critically important for successful implantation during human pregnancy. The polymorphic insertiondeletion (indel) 14-base pair (bp) site localized at the 3' untranslated region was associated with $H L A-G$ mRNA stability and isoform alternative splicing patterns, and thus may influence HLA-G function during pregnancy. We studied the association between the 14-bp indel polymorphism (rs16375) at the 3' untranslated region with recurrent spontaneous abortions in a Saudi population living in Riyadh. A group 
of 64 women with 2-11 successive abortions were included in this study. The control group included 62 women without reported abortions and at least 2 pregnancies, all visiting the King Khaled Hospital in Riyadh. The 14-bp indel was genotyped in the case and control groups. The frequency of the genotype $+14 /+14$ was slightly higher in women with recurrent spontaneous abortions, but no significant differences were observed in the distribution of alleles and genotypes.

Key words: HLA-G; 14-base pair indel polymorphism; Saudi Arabia; Recurrent spontaneous abortions

\section{INTRODUCTION}

The human leukocyte antigen-G gene (HLA-G) is located on the short arm of chromosome 6 within the $H L A$ region (6p21.2-21.3). It consists of 7 introns and 8 exons that code for the heavy chain of the HLA-G molecule. Exons 7 and 8 are always absent in the mature mRNA because of the presence of a stop codon in exon 6 (Donadi et al., 2011). Seven expressed isoforms have been described, 4 of which (HLA-G1-G4) are membranous and 3 (HLA-G5-G7) of which are soluble molecules (Riteau et al., 2001). The proteolytic cleavage of the HLA-G1 isoform generates the soluble HLA-G1 form (O'Brien et al., 2001). Compared to the classical HLA molecules, the $H L A-G$ gene contains a modest 46 polymorphisms that map to either the coding or non-coding regions. At the protein expression level, only 15 variants have been reported (Hviid et al., 2002). The polymorphisms mapped to the non-coding regions, particularly those in the $5^{\prime}$ upstream regulator region (5' UTR) and $3^{\prime}$ untranslated regions (3' UTR), reportedly influence the function of HLA-G molecules and have been implicated in some pathologies such as infertility, preeclampsia, failure in in vitro fertilization, and recurrent spontaneous abortion (RSA) (Menier et al., 2010; Donadi et al., 2011). Several studies have demonstrated the importance of the 3' UTR in the $H L A-G$ expression profile (Rousseau et al., 2003; Martelli-Palomino et al., 2013). This region contains several regulatory elements, including a poly-A signal and AU-rich motifs involved in maintaining mRNA stability and isoform alternative splicing patterns, which may influence the function of HLA-G, particularly during pregnancy (Kovats et al., 1990; Fuzzi et al., 2002). Interestingly, the 14base pair (bp) (5'-ATTTGTTCATGCCT-3') insertion/deletion (indel) polymorphism mapped to position 3741 in the $3^{\prime}$ UTR of exon 8 has gained interest (Harrison et al., 1993; Rousseau et al., 2003). Thus, several reports have indicated that this indel polymorphism is related to $H L A-G$ mRNA stability and splicing patterns involved in generating HLA-G isoforms (Hviid et al., 2003; Rousseau et al., 2003; Chen et al., 2008). Moreover, the 14-bp insertion allele was reported to be associated with low levels of both $H L A-G$ mRNA and circulating soluble HLA-G (sHLA-G) isoforms (Chen et al., 2008; Boukouaci et al., 2011). It was also reported that plasma levels of sHLA-G were dramatically lower with the genotype +14-bp/+14-bp than with +14-bp/-14-bp and -14-bp/-14-bp genotypes (Chen et al., 2008; Martelli-Palomino et al., 2013). Thus, based on the results of several studies, the HLA-G molecule is considered to be a key player during early and mid-term pregnancy by contributing to the maintenance of gestation throughout pregnancy (Kovats et al., 1990; Rouas-Freiss et al., 1997; Fuzzi et al., 2002).

RSA was initially defined as death of the fetus before 24 weeks of gestation at least 2 consecutive times (Regan and Rai, 2000; Stephenson, 2011). It occurs in 2-4\% of reproduc- 
tive-aged women, of which 40-55\% cases remain unexplained (Li et al., 2002; Van den Berg et al., 2014). RSA is one of the most common complications associated with early pregnancy and remains a challenge in gynecology (Jauniaux et al., 2006). Different potential etiologic factors have been implicated in this condition, such as endocrine regulation, autoimmune reaction, thrombophilia, environmental, psychological, and genetic background, and viral infections (Bergant et al., 1997; Bussen et al., 1999; Li et al., 2002; Quenby et al., 2005; Weimar et al., 2012).

The interface between the fetus and mother may contribute to the development and maintenance of the pregnant uterus as an immune-privileged site. In fact, the immunologic relationship between the mother and the fetus is determined by fetal antigens and the maternal immune system. Inadequate recognition of fetal antigens may result in failed pregnancy (Vince and Johnson, 1995; Christiansen, 1996). Since its discovery, the crucial role of the nonclassical HLA-G molecule in pregnancy success has been demonstrated (Ellis et al., 1986; Kovats et al., 1990; Carosella et al., 1999, 2003; Rouas-Freiss et al., 2007). Various studies have reported that HLA-G molecules are responsible for maintaining the immune-regulated and tolerogenic environment during pregnancy (Fuzzi et al., 2002; Criscuoli et al., 2005; Noci et al., 2005). Indeed, these molecules are predominately expressed on extravillous cytotrophoblasts at the fetal-maternal interface during pregnancy (Carosella et al., 1999; Bainbridge et al., 2000; Bhalla et al., 2006). Currently, there is convincing experimental support for expression of HLA-G molecules conferring protection against cytolysis mediated by different maternal cytotoxic subpopulations, such as those of the natural killer cells, T lymphocytes, and dendritic cells. Another study indicated that altered expression of HLA-G molecules is associated with RSA (Vince and Johnson, 1995).

In this study, we examined the association between successful and unsuccessful pregnancies and the $H L A-G$ 14-bp insertion/deletion polymorphism using 2 groups of women: an RSA group and a normal, fertile control group of unrelated women in a Saudi population.

\section{MATERIAL AND METHODS}

\section{Subjects}

This study included 64 cases of Saudi women (mean age $34.18 \pm 6.22$ years) who had RSA and had consulted the King Khaled University Hospital, Riyadh, Saudi Arabia, between January 2010 and January 2011. The control group included 62 (mean age $34.67 \pm 7.75$ years) unrelated, normal fertile Saudi women with 2 or more uncomplicated pregnancies, without a history of RSA, and with at least 2 live births. Patients with anatomical, endocrine, or metabolic disorders or immunodeficiency and autoimmune diseases were excluded from the study. Ethical approval for the study was obtained from the medical ethics committee of King Khalid University Hospital and the ethical committee of King Saud University. All patients and controls provided informed consent and agreed to give blood samples for this case-control study.

\section{Genomic DNA extraction and 14-bp polymorphism genotyping}

Genomic DNA was extracted from peripheral blood using the Puregene purification kit (Qiagen; Hilden, Germany) according to the manufacturer protocol. Exon 8 of the HLA$G$ gene was amplified by polymerase chain reaction (PCR) using the primers GE14HLAG 
(5'-GTGATGGGCTGTTTAAAGTGTCACC-3') and RHG4 (5'-GGAAGGAATGCAGTTCA GCATGA-3') (Hviid et al., 1999).

The PCR protocol consisted of an initial step of denaturation at $94^{\circ} \mathrm{C}$, followed by 35 cycles for $20 \mathrm{~s}$ at $94^{\circ} \mathrm{C}, 30 \mathrm{~s}$ at $64^{\circ} \mathrm{C}$, and $60 \mathrm{~s}$ at $72^{\circ} \mathrm{C}$, as well as a final extension for 10 min at $72^{\circ} \mathrm{C}$. The fragment sizes of the PCR products were analyzed $(220 / 240 \mathrm{bp})$ based on the presence or absence of a specific band on a $3 \%$ agarose gel stained with ethidium bromide and visualized on an ultraviolet transilluminator using a gel documentation system (BioRad Gel225 Doc ${ }^{\mathrm{TM}} \mathrm{XR}+$, Hercules, CA, USA) (Figure 1).

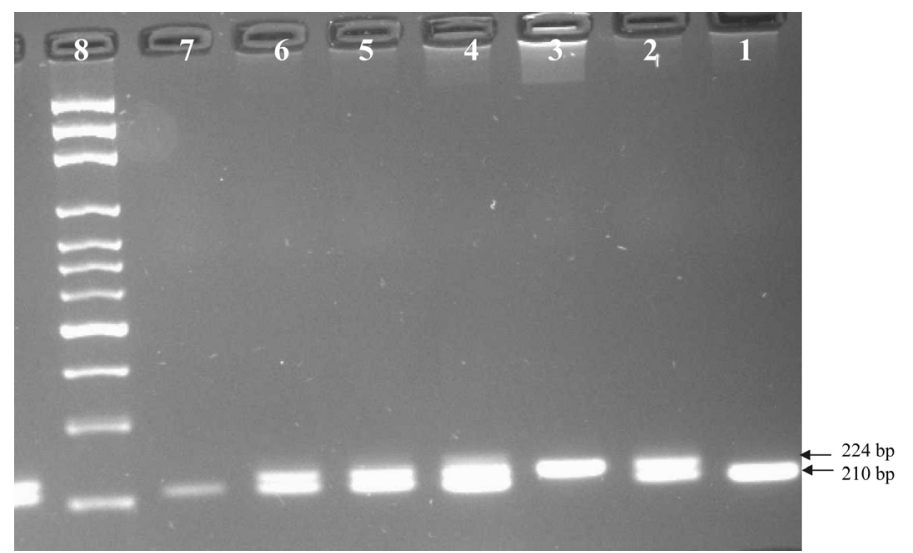

Figure 1. HLA-G 14-bp polymorphism detected on agarose gel. Lanes 1 and 7 are homozygotes $H L A-G-14-b p /-$ $14 \mathrm{bp}$; lanes 2, 4-6 are HLA-G heterozygotes, and lane 3 is the homozygote $H L A-G+14-\mathrm{bp} /+14-\mathrm{bp}$. Lane 8 is the 100-bp DNA ladder.

\section{Statistical analysis}

Frequencies of the $H L A-G 14$-bp indel polymorphism were calculated using the direct counting method. Differences between populations were assessed using a $\chi^{2}$ test and Fisher exact test with the SPSS software (ver. 17.0; SPSS Inc., Chicago, IL, USA). Hardy-Weinberg equilibrium was evaluated for these polymorphisms within each group using the $\chi^{2}$ test. Statistical significance was defined at the $5 \%$ level. We applied Yates correction for continuity and Fisher's exact test (2-tail) when the sample was small.

\section{RESULTS}

In this case-control study, we examined the distribution of alleles and genotypes of the most commonly studied $H L A-G 14-$ bp indel polymorphism among women with at least 3 unexplained RSAs and healthy women with at least 2 live births and without a history of RSA. Clinical and demographic characteristics of the RSA and control subjects are reported in Table 1. We observed that among RSA subjects, the number of spontaneous abortions varied from 3 to 11 . The percentage of women with $3,4,5,6$, 7, and 8-11 RSAs were 37.5, 26.56, 17.2, $4.7,6.25$, and $8 \%$, respectively. Within the RSA group, $36 \%$ of women had no children $(100 \%$ abortions), while for the remaining women, the loss rate was greater than $50 \%$. 
Table 1. Characterization of recurrent spontaneous abortion (RSA) and control healthy women.

\begin{tabular}{|c|c|c|c|c|c|}
\hline Group & $\begin{array}{l}\text { Sample } \\
\text { size }\end{array}$ & Age & $\begin{array}{l}\text { Number of spontaneous } \\
\text { abortions (min-max) }\end{array}$ & $\begin{array}{l}\text { Number of children } \\
\text { (min-max) }\end{array}$ & $\begin{array}{l}\text { Number of pregnancies } \\
(\text { min-max })\end{array}$ \\
\hline Control & 62 & 19-48 & 0 & $2-8$ & $2-8$ \\
\hline RSA & 64 & $18-45$ & $3-11$ & $0-7$ & $0-12$ \\
\hline
\end{tabular}

We found that the $3 H L A-G$ 14-bp genotypes were in Hardy-Weinberg equilibrium $\left(\chi^{2}=0.87, \mathrm{P}=0.35\right)$ in all groups studied. Hardy-Weinberg equilibrium was also verified in women with $\operatorname{RSA}\left(\chi^{2}=0.0006, \mathrm{P}=0.97\right)$ and controls $\left(\chi^{2}=2.08, \mathrm{P}=0.149144\right)$.

The distributions of allele and genotype frequencies of HLA-G 14-bp indel polymorphisms are reported in Table 2. No significant differences in the distribution of allele frequencies between RSA patients and controls or genotypes were observed. In addition, the frequencies of genotypes were comparable in both groups. The frequency of ins/ins homozygote was slightly higher in RSA women compared to controls; however, the difference was not statistically significant $(\mathrm{P}>0.05)$.

Table 2. Distribution of the 14-bp insertion/deletion allele and genotype frequencies in spontaneous abortion patients and control women in Saudi Arabia.

\begin{tabular}{lccccc}
\hline Genotype & Control \% $(\mathrm{N}=62)$ & RSA $\%(\mathrm{~N}=64)$ & Odds ratio & Confidence interval & P value \\
\hline 14-bp insertion & $51(63)$ & $53.9(69)$ & 0.88 & $0.54-1.45$ & 0.71 \\
14-bp deletion & $49(61)$ & $46.1(59)$ & 1.13 & $0.69-1.86$ & 0.71 \\
del//del & $20.9(13)$ & $20.3(13)$ & 0.96 & $0.40-2.27$ & 0.89 \\
ins/ins & $22.6(14)$ & $28.1(18)$ & 1.34 & $0.59-3.00$ & 0.61 \\
Heterozygous allele & $56.5(35)$ & $51.6(33)$ & 0.82 & $0.40-1.65$ & 0.71 \\
\hline
\end{tabular}

To confirm our results, we selected women who did not have children among the RSA group (100\% loss of pregnancies) and those with more than 4 spontaneous abortions. They were compared to a subset of the control group that included women with at least 4 pregnancies. Table 3 shows that the frequency of 14-bp insertion (ins) was not significantly higher in RSA subjects (0.63) than in the control group (0.53). Analysis of genotype distribution between the selected groups revealed a slightly significant difference with the ins/ins homozygote $(\mathrm{P}=0.045)$, but this result was not significant after Yates' correction $(\mathrm{P}=0.065)$.

Table 3. Distribution of the 14-bp insertion/deletion allele and genotype frequencies in a selected group of spontaneous abortion patients without children and RSA $\geq 4$ and control women with at least 4 pregnancies.

\begin{tabular}{|c|c|c|c|c|c|}
\hline Genotype & Control \% $(\mathrm{N}=28)$ & RSA \% $(\mathrm{N}=23)$ & Odds ratio & Confidence interval & $\mathrm{P}$ value \\
\hline 14-bp insertion & $53.6(30)$ & $63.1(29)$ & 1.48 & $0.66-3.27$ & 0.42 \\
\hline 14-bp deletion & $46.4(26)$ & $36.9(17)$ & 0.67 & $0.30-1.49$ & 0.42 \\
\hline del/del & $25(7)$ & $17.39(4)$ & 1.75 & $0.34-6.27$ & 0.8 \\
\hline ins/ins & $17.9(5)$ & $43.48(10)$ & 0.28 & $0.079-1$ & 0.045 \\
\hline Heterozygous allele & $57.1(16)$ & $39.13(9)$ & 2.07 & $0.67-6.37$ & 0.16 \\
\hline
\end{tabular}

\section{DISCUSSION}

Since its discovery by Ellis et al. (1986), the non-classical HLA-G class I molecule has been considered to be a key effector in the immune tolerance of the fetus in pregnant women (Kovats et al., 1990; Rouas-Freiss et al., 1997; Fuzzi et al., 2002). Based on its specific tissue 
distribution and level of expression in the body, this molecule received attention for its potential role in pregnancy disorders. Compared to classical HLA genes, $H L A-G$ is characterized by a low level of polymorphism (Hviid et al., 2003; Menier et al., 2010). Correlations between these polymorphisms, particularly in the 5' UTR and 3' UTR and some pregnancy disorders, have been well-documented. Numerous polymorphic sites have been reported in the 3' UTR (Hviid et al., 1999, 2002). The most thoroughly examined is the 14-bp indel polymorphism that is important in HLA-G expression, mRNA stability, and alternative splicing and is associated with a wide spectrum of diseases, including pregnancy disorders (Wang et al., 2013). Thus, this polymorphic site is an important candidate for studying pregnancy disorders, particularly those with unidentified common factors such as RSA. We conducted this case-control study to investigate whether the 14-bp indel polymorphism located in exon 8 of the $H L A-G$ gene contributes to RSA in a Saudi population. RSA subjects with known etiologic factors such as endocrine disorder, autoimmune reaction, thrombophilia, and environmental or viral infections were excluded from the study. We also selected only those with a history of at least 3 RSAs. The control group living in the same region and visiting the same hospital had no history of RSA and at least 2 live births. The RSA cases and controls were representative random samples of the populations. The first analysis showed that all HLA-G 14-bp genotypes were in Hardy-Weinberg equilibrium. Our results for the distribution of the 14-bp indels polymorphism between all RSA subjects and controls revealed no significant differences. However, for allele frequency, the 14-bp insertion was more frequent in women with RSA than in controls and inversely related to the 14-bp deletion. When comparing only women subjects with at least 4 RSAs and $100 \%$ failed pregnancies and control women having at least 4 successful pregnancies, we observed associations that were borderline significant. Thus, before Yate's correction, the genotype 14 ins/ins was more frequent in women with RSA than in controls (odds ratio $=0.28, \mathrm{P}=0.045$ ). For this 2 apparent association, the confidence interval was very wide and therefore a larger sample for the 2 selected groups is needed to confirm this association. Our results regarding the association study between the 14-bp indel polymorphism and RSA in the Saudi population agree with those reported in other populations such as the Amerindian populations from the Brazilian Amazon, Finnish, Hungarian, Polish, Japanese, Danish, Chinese, and some Indian populations (Hviid et al., 2002; Yan et al., 2006; Xue et al., 2007; Aruna et al., 2010). However, in other studies, the association between the $H L A-G$ 14-bp polymorphism and RSA were confirmed in some Indian and Chinese populations (Shankarkumar et al., 2011). However in a previous study in an Indian population, the $H L A-G$ 14-bp polymorphism was not associated with RSA disorder (Tripathi et al., 2004). Recently, to assess the strength of the association between the HLA-G 14-bp polymorphism and RSA, a meta-analysis based on 14 studies examining the association in different populations were controversial. This analysis confirmed a strong association between the ins (+14-bp) allele and RSA risk. However, the association between the heterozygote (-14-bp/+14bp) and RSA remains controversial (Wang et al., 2013).

Although our data excluded a significant association between this polymorphic site and RSA, a larger case-control study including other polymorphic sites of the $H L A-G$ gene is necessary to substantiate the importance of $H L A-G$ polymorphisms and linkage disequilibrium in RSA risk.

\section{ACKNOWLEDGMENTS}

The authors would like to thank the Deanship of Scientific Research at King Saud 
University for funding this study through the Research Project no \#NFG2-12-33.

\section{REFERENCES}

Aruna M, Sudheer PS, Andal S, Tarakeswari S, et al. (2010). HLA-G polymorphism patterns show lack of detectable association with recurrent spontaneous abortion. Tissue Antigens 76: 216-222.

Bainbridge DR, Ellis SA and Sargent IL (2000). The short forms of HLA-G are unlikely to play a role in pregnancy because they are not expressed at the cell surface. J. Reprod. Immunol. 47: 1-16.

Bergant AM, Reinstadler K, Moncayo HE, Solder E, et al. (1997). Spontaneous abortion and psychosomatics. A prospective study on the impact of psychological factors as a cause for recurrent spontaneous abortion. Hum. Reprod. 12: 1106-1110.

Bhalla A, Stone PR, Liddell HS, Zanderigo A, et al. (2006). Comparison of the expression of human leukocyte antigen (HLA)-G and HLA-E in women with normal pregnancy and those with recurrent miscarriage. Reproduction 131: 583-589.

Boukouaci W, Busson M, Fortier C, Amokrane K, et al. (2011). Association of HLA-G low expressor genotype with severe acute graft-versus-host disease after sibling bone marrow transplantation. Front. Immunol. 2: 74.

Bussen S, Sütterlin M and Steck T (1999). Endocrine abnormalities during the follicular phase in women with recurrent spontaneous abortion. Hum. Reprod. 14: 18-20.

Carosella ED, Dausset J and Rouas-Freiss N (1999). Immunotolerant functions of HLA-G. Cell. Mol. Life Sci. 55: $327-$ 333.

Carosella ED, Moreau P, Le Maoult J, Le Discorde M, et al. (2003). HLA-G molecules: from maternal-fetal tolerance to tissue acceptance. Adv. Immunol. 81: 199-252.

Chen XY, Yan WH, Lin A, Xu HH, et al. (2008). The 14-bp deletion polymorphisms in HLA-G gene play an important role in the expression of soluble HLA-G in plasma. Tissue Antigens 72: 335-341.

Christiansen OB (1996). A fresh look at the causes and treatments of recurrent miscarriage, especially its immunological aspects. Hum. Reprod. Update 2: 271-293.

Criscuoli L, Rizzo R, Fuzzi B, Melchiorri L, et al. (2005). Lack of Histocompatibility Leukocyte Antigen-G expression in early embryos is not related to germinal defects or impairment of interleukin-10 production by embryos. Gynecol. Endocrinol. 20: 264-269.

Donadi EA, Castelli EC, Arnaiz-Villena A, Roger M, et al. (2011). Implications of the polymorphism of HLA-G on its function, regulation, evolution and disease association. Cell. Mol. Life Sci. 68: 369-395.

Ellis SA, Sargent IL, Redman CW and McMichael AJ (1986). Evidence for a novel HLA antigen found on human extravillous trophoblast and a choriocarcinoma cell line. Immunology 59: 595-601.

Fuzzi B, Rizzo R, Criscuoli L, Noci I, et al. (2002). HLA-G expression in early embryos is a fundamental prerequisite for the obtainment of pregnancy. Eur. J. Immunol. 32: 311-315.

Harrison GA, Humphrey KE, Jakobsen IB and Cooper DW (1993). A 14-bp deletion polymorphism in the HLA-G gene. Hum. Mol. Genet. 2: 2200.

Hviid TV, Sorensen S and Morling N (1999). Polymorphism in the regulatory region located more than 1.1 kilobases $5^{\prime}$ to the start site of transcription, the promoter region, and exon 1 of the HLA-G gene. Hum. Immunol. 60: 1237-1244.

Hviid TV, Hylenius S, Hoegh AM, Kruse C, et al. (2002). HLA-G polymorphisms in couples with recurrent spontaneous abortions. Tissue Antigens 60: 122-132.

Hviid TV, Hylenius S, Rorbye C and Nielsen LG (2003). HLA-G allelic variants are associated with differences in the HLA-G mRNA isoform profile and HLA-G mRNA levels. Immunogenetics 55: 63-79.

Jauniaux E, Farquharson RG, Christiansen OB and Exalto N (2006). Evidence-based guidelines for the investigation and medical treatment of recurrent miscarriage. Hum. Reprod. 21: 2216-2222.

Kovats S, Main EK, Librach C, Stubblebine M, et al. (1990). A class I antigen, HLA-G, expressed in human trophoblasts. Science 248: 220-223.

Li TC, Makris M, Tomsu M, Tuckerman E, et al. (2002). Recurrent miscarriage: aetiology, management and prognosis. Hum. Reprod. Update. 8: 463-481.

Martelli-Palomino G, Pancotto JA, Muniz YC, Mendes-Junior CT, et al. (2013). Polymorphic sites at the 3' untranslated region of the HLA-G gene are associated with differential hla-g soluble levels in the Brazilian and French population. PLoS One 8: e71742.

Menier C, Rouas-Freiss N, Favier B, LeMaoult J, et al. (2010). Recent advances on the non-classical major histocompatibility complex class I HLA-G molecule. Tissue Antigens 75: 201-206.

Noci I, Fuzzi B, Rizzo R, Melchiorri L, et al. (2005). Embryonic soluble HLA-G as a marker of developmental potential 
in embryos. Hum. Reprod. 20: 138-146.

O’Brien M, McCarthy T, Jenkins D, Paul P, et al. (2001). Altered HLA-G transcription in pre-eclampsia is associated with allele specific inheritance: possible role of the HLA-G gene in susceptibility to the disease. Cell. Mol. Life Sci. 58: 1943-1949.

Quenby S, Farquharson RG, Dawood F, Hughes AM, et al. (2005). Recurrent miscarriage and long-term thrombosis risk: a case-control study. Hum. Reprod. 20: 1729-1732.

Regan L and Rai R (2000). Epidemiology and the medical causes of miscarriage. Baillieres Best Pract. Res. Clin. Obstet. Gynaecol. 14: 839-854.

Riteau B, Rouas-Freiss N, Menier C, Paul P, et al. (2001). HLA-G2, -G3, and -G4 isoforms expressed as nonmature cell surface glycoproteins inhibit NK and antigen-specific CTL cytolysis. J. Immunol. 166: 5018-5026.

Rouas-Freiss N, Gonçalves RM, Menier C, Dausset J, et al. (1997). Direct evidence to support the role of HLA-G in protecting the fetus from maternal uterine natural killer cytolysis. Proc. Natl. Acad. Sci. U. S. A. 94: 11520-11525.

Rouas-Freiss N, Naji A, Durrbach A and Carosella ED (2007). Tolerogenic functions of human leukocyte antigen G: from pregnancy to organ and cell transplantation. Transplantation 84: S21-S25.

Rousseau P, Le Discorde M, Mouillot G, Marcou C, et al. (2003). The 14-bp deletion-insertion polymorphism in the 3'UT region of the HLA-G gene influences HLA-G mRNA stability. Hum. Immunol. 64: 1005-1010.

Shankarkumar U, Shankarkumar A, Chedda Z and Ghosh K (2011). Role of 14-bp deletion/insertion polymorphism in exon 8 of the HLA-G gene in recurrent spontaneous abortion patients. J. Hum. Reprod. Sci. 4: 143-146.

Stephenson MD (2011). Recurrent early pregnancy loss. Semin. Reprod. Med. 29: 461-462.

Tripathi P, Abbas A, Naik S and Agrawal S (2004). Role of 14-bp deletion in the HLA-G gene in the maintenance of pregnancy. Tissue Antigens 64: 706-710.

Van den Berg MM, Vissenberg R and Goddijn M (2014). Recurrent miscarriage clinics. Obstet. Gynecol. Clin. North Am. 41: 145-155.

Vince GS and Johnson PM (1995). Materno-fetal immunobiology in normal pregnancy and its possible failure in recurrent spontaneous abortion? Hum. Reprod. 10 (Suppl 2): 107-113.

Wang X, Jiang W and Zhang D (2013). Association of 14-bp insertion/deletion polymorphism of HLA-G gene with unexplained recurrent spontaneous abortion: a meta-analysis. Tissue Antigens 81: 108-115.

Weimar CH, Kavelaars A, Brosens JJ, Gellersen B, et al. (2012). Endometrial stromal cells of women with recurrent miscarriage fail to discriminate between high- and low-quality human embryos. PLoS One 7: e41424.

Xue S, Yang J, Yao F, Xu L, et al. (2007). Recurrent spontaneous abortions patients have more $-14 \mathrm{bp} /+14 \mathrm{bp}$ heterozygotes in the 3'UT region of the HLA-G gene in a Chinese Han population. Tissue Antigens 69 (Suppl 1): 153-155.

Yan WH, Lin A, Chen XJ, Dai MZ, et al. (2006). Association of the maternal 14-bp insertion polymorphism in the HLA-G gene in women with recurrent spontaneous abortions. Tissue Antigens 68: 521-523. 